\title{
Formação inventiva de uma professora-pesquisadora no encontro com mulheres ciganas: pesquisa-intervenção e estudos foucaultianos
}

\author{
Inventive training of a teacher-researcher in the encounter with Roma \\ women: research-intervention and Foucault studies
}

\section{Gláucia Siqueira Marcondes; Anderson Ferrari}

Secretaria de Educação do Estado de Minas Gerais; Universidade Federal de Juiz de Fora

\section{RESUMO:}

O foco da análise empreendida neste artigo é a formação inventiva de uma professorapesquisadora no encontro com mulheres ciganas. O texto é desdobramento de uma pesquisa mais abrangente em que problematizamos o processo de constituição de três mulheres ciganas em um acampamento na cidade de Juiz de Fora/MG. Para isso, utilizamos a perspectiva foucaultiana como embasamento teórico-metodológico, sobretudo os modos de constituição dos sujeitos e os efeitos dos discursos nas formas de conhecer, de ser e de estar no mundo. Ao longo da investigação, as relações de gênero e o sentido de educação foram as questões que mais chamaram atenção nas falas da professora-pesquisadora, que serão tomadas como análise.

Palavras-chave: mulheres ciganas; formação inventiva; sujeito; saber.

\begin{abstract}
:
It is the inventive training of a teacher-researcher in the encounter with Roma women that is the focus of our analysis. It is a text, therefore, which is the result of a more comprehensive research in which we problematize the process of constituting three Roma women in a camp in the city of Juiz de Fora / MG. For this, we used the Foucaultian perspective as a theoretical-methodological basis, especially the ways of constituting the subjects and the effects of the speeches on the ways of knowing, being and being in the world. Throughout the investigation, it was gender relations and the sense of education that drew the most attention in the speeches of the teacherresearcher, which will be taken as analysis.
\end{abstract}

Key-words: gypsy women, inventive training, subject, knowledge

DOI: 10.12957/mnemosine.2020.52684

\section{Introdução}

Em 1968, Michel Foucault concedeu uma entrevista a Claude Bonnefoy, um renomado crítico literário da revista Arts, em que falava sobre a arte de escrever, seus limites e suas potencialidades (FOUCAULT, 2016). O autor francês tinha acabado de lançar a Arqueologia do Saber, em que faz uma espécie de história das ciências vinculada aos processos históricos. Interessado na relação de Foucault com a escrita, o 
entrevistador foca grande parte da entrevista nessa preocupação sobre o que seria o ato de escrever. "Escrever era fazer vento" (FOUCAULT, 2016: 39), respondeu Foucault ao pensar sua relação com a escrita a partir de suas experiências com outras realidades e línguas.

No final, a única pátria real, o único chão sobre o qual se pode andar, a única casa onde podemos nos deter e nos abrigar é a língua, aquela que aprendemos desde a infância. Tratou-se para mim, então, de reanimar essa lingua, de construir para mim uma espécie de casinha da linguagem da qual eu seria o dono e conheceria cada cantinho. Acho que foi isso que me deu vontade de escrever. Entre prazer de escrever e possibilidade de falar, existe certa relação de incompatibilidade. Ali onde não é mais possivel falar, descobre-se o encanto secreto, difícil, um pouco perigoso de escrever (FOUCAULT, 2016: 39).

A citação nos provoca a pensar em duas questões importantes para a formação inventiva de professoras: o que nos motiva a escrever? Qual a relação da escrita com o exercício de se reinventar? Assim, seguindo as trilhas do "encanto e perigo" de escrever é que vamos focar nossa análise na formação inventiva de uma professora-pesquisadora no seu encontro com mulheres ciganas. Uma formação que se deu no encontro entre a formação inicial, a formação da subjetividade como mulher-professora, a formação continuada num Programa de Pós-graduação em Educação e no processo de estranhamento e encantamento com mulheres ciganas. Nesse sentido, este artigo é um desdobramento de uma pesquisa de mestrado em Educação, intitulada Entre exuberância e mistério: subjetividades de mulheres ciganas nas interfaces entre educação e gênero, desenvolvida entre 2018 e 2020, que problematizou o processo de constituição de mulheres ciganas em um acampamento na cidade de Juiz de Fora/MG.

Não é por acaso que "exuberância" e "mistério" compõem o título do trabalho. São duas palavras que consideramos essenciais para compreender o processo de escolha em pesquisar com mulheres ciganas, para pensar a curiosidade inicial que levou à investigação e para dar lugar aos efeitos da pesquisa na pesquisadora. As vestimentas coloridas e os adereços usados por muitas dessas mulheres chamam atenção. O termo "exuberância" está relacionado a esse modo de vestir, que é percebido por muitas pessoas como fascinante, extravagante e diferente. Mas "exuberância" também se mistura ao "mistério", atribuído ao desconhecimento em relação à cultura cigana, uma incompreensão que leva, muitas vezes, à curiosidade e ao interesse, mas também ao preconceito e à intolerância. Em meio a esses entendimentos que ajudaram a definir o título, a professora-pesquisadora relaciona esses encantamentos e mistérios ao processo de pesquisar, de escrever e de se constituir como mulher: 
"Essa compreensão diz do modo como fui subjetivada em relação às mulheres ciganas. Os encontros com essas mulheres ciganas em seus processos de constituição dialogam com o meu processo de construção do feminino, de maneira que esses encontros e diálogos também dizem de aflições e situações espinhosas que marcam esses momentos de renovação. Não foi tranquilo para mim colocar sob suspeita "verdades" que me constituíram desde criança sobre as mulheres ciganas. No entanto, tal mudança, apesar de difícil e dolorosa, potencializou novos encontros comigo mesma, com a minha existência e minha constituição ${ }^{1}$."

Ao escrever sobre os efeitos da pesquisa, a professora-pesquisadora fala de uma mudança que, apesar de "difícil" e "dolorosa", também possibilitou novos encontros consigo mesma. A escrita dá vida à experiência de transformação pelo conhecimento, pela problematização daquilo que se sabe, para saber diferente. É esse processo de escrever e se estranhar, escrever e colocar sob suspeita o que se sabe, escrever e se transformar que queremos trazer à tona para pensar a formação inventiva dessa professora-pesquisadora, que, ao final do trabalho, se constitui como outra, diferente daquela que iniciou a pesquisa. Portanto, vamos trabalhar, neste artigo, com as falas da professora-pesquisadora no seu processo de mudança do pensamento como parte da sua formação como sujeito e como professora, algo que se deu no encontro com a pesquisa e com a escrita. As falas da professora-pesquisadora nos convidam a pensar na formação inventiva de professoras nos encontros entre a universidade, a escola básica e outras realidades culturais e educativas.

Uma formação inventiva, então, se liga aos territórios escolares para provocar um exercício de colocar a atenção no presente e desformar, mais do que formar. Uma prática de resistência que ganha expressão pelas políticas de cognição (Dias; Kastrup, 2013) que nos passam. Mais do que se opor, resistimos para liberar e talvez. diferir daquilo que a aprisiona. Uma formação inventiva se esforça para manter vivo um campo problemático (DIAS, 2015: 195).

É esse campo problemático de investigação que vai sendo desenhado em meio à inquietação dos discursos que constituíram a professora, num exercício de se libertar das amarras do pensamento.

O pensamento não é o que se presentifica em uma conduta e lhe dá um sentido; é, sobretudo, aquilo que permite tomar uma distância em relação a essa maneira de fazer ou de reagir, e tomá-la como objeto de pensamento e interrogá-la sobre seu sentido, suas condições e seus fins. O pensamento é liberdade em relação àquilo que se faz, movimento pelo qual dele nos separamos, constituímo-lo como objeto e pensamo-lo como problema (FOUCAULT, 2006: 231-232). 
A preocupação era pensar os processos educativos envolvidos na constituição das subjetividades de três mulheres ciganas que moram em uma comunidade cigana de Juiz de Fora: Esmeralda, Yasmim e Carmelita ${ }^{2}$. Esta pesquisa foi tomando forma no encontro entre as conversas com essas três mulheres e os escritos que se aproximam da perspectiva foucaultiana. Através deles, foi possível pensar e questionar "como nos tornamos isso que nós somos, como nos tornamos sujeitos de experiências e como elas nos constituem" (FERRARI, 2012: 38). A escrita que pretendemos aqui é aquela que mobiliza nossas formas de pensar e agir com as mulheres ciganas, com os sujeitos nas suas relações conosco e com nossas constituições e com o que somos capazes de produzir de conhecimentos sobre nós mesmos.

\section{Problematização como caminho investigativo}

A aproximação com o campo aconteceu por intermédio da vice-diretora da escola municipal próxima ao acampamento, que se mostrou solícita para marcar o primeiro encontro e acompanhar na primeira visita. No primeiro encontro, ao saber que se tratava de uma professora interessada pela cultura e pelas mulheres ciganas, Esmeralda se sentiu à vontade para dizer de sua demanda pela aprendizagem da leitura e da escrita, já que não sabia ler nem escrever com fluência. A cigana, muito feliz, perguntou se poderia convidar outras ciganas para participarem dos estudos, que seriam realizados no interior do próprio acampamento. Dessa forma, o próprio campo é que foi definindo o procedimento da investigação. Foram as mulheres ciganas que, interessadas em aprender a ler e escrever, colocaram-se à disposição para conversar sobre o que significava ser cigana. O campo seria construído em conjunto, entre essas mulheres, cabendo à professora-pesquisadora aguçar os sentidos para escutar com atenção, apresentar-se com disposição para o encontro, olhar nos detalhes.

As "aulas" não foram mera codificação e decodificação do sistema de escrita. Foram encontros que disseram de sujeitos, de experiências, de educação e de processos de constituição. Desse modo, a metodologia utilizada foi além de observar uma cultura e ensinar mulheres ciganas a ler e escrever. Foram utilizados, como procedimento, encontros criativos, participativos e produtivos em que a escrita propiciava que emergissem as questões da constituição de si. Encontros em que as ciganas

participaram, compartilharam conhecimentos e experiências de vida, que produziram saberes, relações de poder, constituíram subjetividades e modos de ser. 
"Nesses encontros, conversamos! Partilhamos alegrias, tristezas, aflições, emoções e preocupações diversas. Desse modo, questiono: a conversa poderia ser uma metodologia de pesquisa?"

Com isso, queremos problematizar "a metodologia hegemônica, tão bem representada por questionários, roteiros, procedimentos rígidos" e apostar em uma pesquisa-intervenção baseada na conversação. Conversar pareceu-nos "ser uma linha de fuga às normativas da pesquisa científica" (RIBEIRO; SAMPAIO; SOUZA, 2018: 29). Desse modo, posicionamo-nos fora da metodologia que "zela pelos procedimentos, técnicas e instrumentos de pesquisa reproduzíveis, em prol de um conhecimento neutro, objetivo e inconteste, tal qual planteou a modernidade positivista" (RIBEIRO; SAMPAIO; SOUZA, 2018:167).

A conversa como metodologia de pesquisa-intervenção abre espaço para interrogarmos os "modos autoritários e, muitas vezes arrogantes, de pesquisar" (RIBEIRO; SAMPAIO; SOUZA, 2018: 34). É um modo de pesquisar que possibilita sair das posições rígidas criadas em torno da relação pesquisador(a) e sujeitos da pesquisa. "O conversar pressupõe a circulação da palavra, numa perspectiva de desestabilizar relações de poder verticalizadas" (RIBEIRO; SAMPAIO; SOUZA, 2018: 34). A conversa, nesse sentido, preza por uma relação mais democrática, pois retira do centro aquele(a) que domina e controla o assunto e o tempo da fala. Na conversa com as mulheres ciganas, foram priorizados a escrita e o que vinha como reflexão, de maneira que a escuta do que elas diziam também foi fundamental, sendo mais importante ouvilas no sentido de valorizar suas narrativas, seus conhecimentos e experiências de vida. Nesse sentido, podemos dizer que, ao fazer essa pesquisa-intervenção, estávamos envolvidos e implicados numa disputa pelo processo de significação e construção de identidades, que nos potencializa a questionar: quem está autorizado ou tem o direito de falar? Em que espaços estão autorizados a falar e como exercem esse direito de falar? Se as ciganas não contarem suas experiências, histórias de vida, desafios e alegrias do lugar em que se encontram, elas serão narradas a partir de outros lugares, aprisionadas em posições de sujeito, espaços, identidades que comprometem as possibilidades de desconstruir saberes que as controlam e as regulam.

Nessa perspectiva, a conversa pressupõe a imprevisibilidade, a contingência e o inesperado do acontecimento. As conversas com as ciganas borraram os contornos do esperado, desarrumaram o ordenado, extrapolaram aquilo que havia sido pensado para trabalhar nas aulas. "Como saber aonde chegará uma conversa?" (RIBEIRO; 
SAMPAIO; SOUZA, 2018:1 65). Embora esses encontros fossem pautados e planejados com antecedência, no decorrer das conversas eram transformados e tornavam-se outra coisa, com novos objetivos, interesses e desafios.

A pesquisa-intervenção pode ser pensada como uma estratégia ligada à "vontade de saber", que é inseparável da "vontade de poder". A vontade de saber e a vontade de poder se articulam no arcabouço foucaultiano com a ideia de que "conhecer é governar", de maneira que estamos nos apropriando dessas combinações teóricas para dizer que a pesquisa-intervenção com as mulheres ciganas se desenvolveu motivada pelo desejo de conhecer, mas que, ao se realizar, produziu discursos que instituíram realidades. A pesquisa-intervenção e o seu desdobramento na escrita do trabalho criaram uma realidade, o que não deixa de ser uma forma de capturar significados atravessados pelas relações de poder. Podemos dizer que existem dois sujeitos mulheres: a professora-pesquisadora não cigana que narra e as três mulheres ciganas que são narradas, visto que suas histórias tomam vida pela escrita da dissertação. A princípio, poderíamos cair na armadilha de considerar que a professora-pesquisadora exerce o poder e estaria livre dele. No entanto, quem exerce o poder não está livre dele, visto que ele opera em várias direções, ele circula entre elas, de maneira que quem narra também é narrado. Ao escutar, ao narrar e ao escrever sobre as mulheres, a professorapesquisadora também fala de si, se desconhece na medida em que conhece e escuta as mulheres ciganas.

O motivo que me impulsionou foi muito simples [...] É a curiosidade - em todo caso, a única espécie de curiosidade que vale a pena ser praticada com um pouco de obstinação: não aquela que procura assimilar o que convém conhecer, mas a que permite separar-se de si mesmo. De que valeria a obstinação do saber se ele assegurasse apenas a aquisição dos conhecimentos e não, de certa maneira, e tanto quanto possível, o descaminho daquele que conhece? (FOUCAULT, 1984: 13 - grifo nosso)

Em História da Sexualidade II: o uso dos prazeres, Foucault escreve sobre essa curiosidade que valeria a pena ser praticada como um exercício, aquela que coloca em movimento o processo de separação do sujeito em relação a si mesmo. Essa experiência de dar um passo atrás em relação ao pensamento é necessária para transformar os modos de ver as coisas do mundo, da vida, da história e dos sujeitos. O filósofo nos inspira quando diz que "existem momentos na vida onde a questão de saber se se pode pensar diferentemente do que se pensa, e perceber diferentemente do que se vê é indispensável para continuar a olhar ou a refletir" (FOUCAULT, 1984: 13). 


\begin{abstract}
"Ao longo da pesquisa, exercitei a curiosidade para pensar de outra maneira a cultura cigana, as questões de gênero, os processos de subjetivação e educação dos sujeitos. Até pouco antes de entrar no mestrado, tinha convicção de que todos (as) os (as) ciganos (as), sem exceção, eram enganadores(as), trapaceiros(as), ladrões(as), feiticeiros(as) e preguiçosos(as). Também atribuía a escola como único lugar de educação dos sujeitos, do mesmo modo pensava em um processo de subjetivação único para todas as mulheres ciganas. Nesse sentido, tenho me esforçado para desconfiar desses pensamentos, na tentativa de transformar essas certezas em dúvidas e inquietações".
\end{abstract}

Dois processos de mudança são identificados ao final da pesquisa, ambos ligados a um conhecimento prévio sobre o que são os(as) ciganos(as) e o que são a escola e a educação. Existe, portanto, um antes e um depois do mestrado. Um antes marcado por uma forma de conhecer os(as) ciganos(as), de maneira homogênea, como se "todos(as)" fossem enganadores(as), trapaceiros(as), ladrões(as), feiticeiros(as) e preguiçosos(as). Mas também existia uma forma de pensar a escola como único lugar de educação dos sujeitos. O que essa fala nos provoca é o exercício de transformação, pela pesquisa e pela escrita, na medida em que a professora-pesquisadora demonstra que precisamos estar abertos(as) para discordar do que pensávamos até pouco tempo atrás. A rigor, não podemos nos fazer seguidores fiéis de ninguém: nem de nós mesmos(as). Por tudo isso, o "pensar de outro modo" é um exercício difícil e arriscado" (LOPES \& VEIGA-NETO, 2010: 160). Pensar de outro modo não significa simplesmente acumular e acrescentar conhecimentos sobre aquilo que já se pensa e já se sabe. É, ao contrário, um movimento que desestabiliza e desterritorializa o já conhecido, na busca de outras possibilidades de pensamento. Trata-se, portanto, de um processo difícil e arriscado, pois coloca o sujeito numa viagem cujo destino e ponto de chegada são desconhecidos. Assim, fazer essa viagem "exige levantar as âncoras, desacomodar-se e deixar para trás o que parecia ser um porto seguro LOPES \& VEIGA-NETO, 2010: 159).

Mover-se nas pesquisas é como se mover nas águas; em alguns momentos, presenciamos sua calmaria, em outros, sua agitação e turbulência. O contato com uma cultura diferente pode se aproximar à sensação de estar em alto mar, na agitação das águas, com muitos perigos a enfrentar, como o medo e o pavor em relação aos(às) ciganos(as).

"O balanço e a imprecisão das águas me tirou do lugar e me transformou”.

De acordo com Ailton Dias de Melo, Cláudia Maria Ribeiro e Gislaine de Fátima Ferreira da Silva (2016), as águas revoltas têm um potencial de imprecisão e de transformação, elas “evocam agitação, fúria, verdadeiras perturbações. São anúncio de 
um novo nem sempre previsível. Revoltas e em tempestades manifestam epifanias, forças ocultas e transformadoras". As águas "revoltas possuem um encanto que reside na indefinição, nas contradições. São águas paradoxais que tudo podem” (MELO; RIBEIRO; SILVA, 2016: 234).

"Foi muito difícil e arriscado aventurar-me na cultura cigana, mas arrisquei-me e descobri a potencialidade desta viagem. Posso afirmar que voltei dessa viagem com um olhar diferente. Hoje vejo as mulheres ciganas de um outro modo, como pessoas que sofrem, se divertem, têm sonhos, saudades e muito amor pela família e sua cultura. São mulheres fortes, que lutam contra o preconceito e resistem às dificuldades da vida."

Essa mudança de olhar não seria possível sem a problematização, sem o distanciamento e o estranhamento do pensamento. Distanciar, desprender e interrogar o próprio pensamento seria liberdade para Foucault. "O pensamento é liberdade em relação àquilo que se faz, o movimento pelo qual dele nos separamos, constituímo-lo como objeto e pensamo-lo como problema" (FOUCAULT, 2006: 231-232). Para que o pensamento se torne um problema, é preciso "que um certo número de fatores os tenha feito perder a familiaridade ou provocado um certo número de dificuldades" (FOUCAULT, 2006: 231). Esse movimento exige estranhamento e distanciamento em relação ao pensamento, que é comum e íntimo. Esse processo de suspeita do conhecimento sobre a cultura cigana provocou atitudes diferentes diante desse saber.

De acordo com Rosa Fischer (2007), é preciso "desviar o olhar dessa "naturalidade" que nos espreita, e depositar nossa atenção sobre esta ou aquela prática bem datada, localizada" (FISCHER, 2007: 61). Portanto, as experiências compartilhadas através desta pesquisa foram ditas a partir de práticas muito particulares e localizáveis. As subjetividades das mulheres ciganas foram pensadas dentro de um contexto histórico específico de discursos e relações de saber e poder. Quando falamos de subjetividades, "estamos nos referindo a esses processos organizados e que organizam práticas de si que têm nos discursos e na relação saber-poder suas forças, mas que demonstram também a descontinuidade das formas históricas (FERRARI, 2010: 9). Pensar essas subjetividades como resultados de processos múltiplos e diferenciados é se ater para a variedade de fatores que interferem na sua construção. Ferrari (2010) utiliza "subjetividades" no plural, mostrando que pode existir uma pluralidade de formas de se constituírem sujeitos. As forças discursivas são grandes para manter a continuidade das formas históricas pelas quais essas mulheres foram e são subjetivadas, mas não podemos descartar a possibilidade desse rompimento. Como 
Ferrari (2010) argumenta, os processos subjetivos podem ser desfeitos, dando lugar a outros modos de construção do sujeito. Não queremos cair na armadilha do conhecimento totalizante sobre os processos de subjetivação das mulheres ciganas.

Para Foucault (2006: 225), "aquele que questiona nada mais faz do que usar um direito que lhe é dado: não ter certeza, perceber uma contradição, ter necessidade de uma informação suplementar, defender diferentes postulados, apontar um erro de raciocínio". Pesquisar e escrever, nesse sentido, não significa estabelecer modelos seguros de pesquisa, nem definir, a priori, o percurso, o caminho, o trajeto a ser feito. No entanto, isso não significa, tampouco, não inscrever e mesmo negar nossa ação nos "regimes de verdade", como defende Foucault. Mas a pesquisa também constrói verdades na medida em que se inscreve nos discursos de autoridade, já que se configura como um produto final - dissertação de mestrado -, com metodologia, com perspectiva teórica, enfim, com os aspectos de um trabalho científico. A pesquisa foi ao encontro das dúvidas, das perguntas, das contradições, daquilo que até pouco tempo era impensável, no sentido de questionar as certezas e as verdades do pensamento. Seria um movimento de pensamento que critica o sujeito racional e autônomo, as pretensões universais da razão e as metanarrativas de explicação do mundo. Para Guacira Lopes Louro, conhecer, pesquisar e escrever "significa resistir à pretensão de operar com «a verdade». Implica entender que qualquer verdade ou certeza (incluindo, obviamente, as nossas) está ancorada no que é possível conhecer num dado momento, portanto é provisória, situada" (LOURO, 2007: 241).

Ao "final" do trabalho, foi possível pensar a cultura cigana, os processos subjetivos das mulheres ciganas e a educação com um olhar mais aberto e menos engessado. Um processo de mudança resultado da aposta em uma pesquisa que enveredou pelos caminhos da problematização do pensamento. Dar um passo atrás em relação à maneira de pensar e agir foi essencial nesse processo. Marshall (2008) dialoga com Foucault a respeito disso:

Dar um passo para trás é, ao mesmo tempo, uma liberdade para Foucault. É a liberdade de separar-se do que se faz, é o movimento pelo qual alguém se separa do que se faz, de forma a estabelecê-lo como um objeto de pensamento e a refletir sobre ele como um problema... Questionar significados, condições e metas é ao mesmo tempo liberdade em relação ao que se faz. É tratar o objeto de pensamento como um problema. Um sistema de pensamento seria uma história de problemas ou uma problematização. Envolveria o desenvolvimento de um conjunto de condições nas quais possíveis respostas pudessem ser propostas. Mas não se apresentaria como uma solução ou resposta (MARSHALL, 2008: 31). 
Esse parece ser um caminho possível de se fazer pesquisa: "dar esse passo atrás" para pensar, sob uma nova ótica, aquilo que pareceu, até recentemente, inquestionável e naturalizado.

\section{Experiência na pesquisa e na escrita: subjetividades, educação e gênero}

Pensar a trajetória de pesquisa de uma professora no mestrado em Educação é um investimento num sentido de educação que amplia o interesse para os processos de constituição dos sujeitos como educativos. Nesse sentido, não nos interessa somente o que ocorre na escola, mas para além dela, explorando os processos de constituição dos sujeitos ligados aos saberes e relações de poder que nos formam. Primeiro, porque participar de um programa de pós-graduação não é, simplesmente, pesquisar e escrever uma dissertação, mas algo maior que diz de processos de transformação do sujeito.

"A cada nova experiência no mestrado deixei para trás parte do que eu era para me reinventar, e isso possibilitou potentes transformações ao longo da caminhada".

Segundo, porque pesquisar e escrever diz do encontro com o desconhecido, de maneira que escrever uma dissertação não é confirmar o que já se sabe, mas uma aposta no campo empírico como espaço que nos convida a colocar sob suspeita nossas formas de saber, pensar e agir.

As amarras e as verdades enraizadas, muitas vezes, nos impedem de transformar nossos modos de ser e viver, mas acreditamos na possibilidade da experiência na pesquisa e na escrita. Mas afinal, o que estamos chamado de experiência? Assumimos o conceito de experiência tal como ele é tratado por Michel Foucault, como algo que produz sentido, subjetividade e tem a possibilidade de modificar o sujeito. Seria uma experiência concreta, que está relacionada às particularidades do sujeito, de sua história e da sua cultura.

Em História da Sexualidade II, Michel Foucault propôs-se a pensar a experiência da sexualidade como uma experiência histórica. Falar da 'sexualidade' como experiência historicamente singular suporia pensar em três eixos que a constituem: "a formação dos saberes que a ela se referem, os sistemas de poder que regulam sua prática e as formas pelas quais os indivíduos podem e devem se reconhecer como sujeitos dessa sexualidade" (FOUCAULT, 1984: 10). Roney Polato de Castro (2014) enfatiza que essa experiência histórica "cria o sujeito, os modos de subjetivação, 
os jogos de verdade por meio dos quais o ser se constitui historicamente como podendo e devendo ser pensado" (CASTRO, 2014: 20).

“As minhas experiências com as mulheres ciganas são experiências históricas que dizem de mim, dos meus processos de subjetivação. Outras experiências, de outros sujeitos podem produzir outros modos de constituição em relação a essas mulheres".

Foucault argumenta que "uma experiência é sempre uma ficção; é algo que se fabrica para si mesmo, que não existe antes e que existirá depois" (FOUCAULT, 1984: 45). A experiência, sendo produção, criação, singularidade e acontecimento, afeta os sujeitos de múltiplas maneiras. Portanto, não temos a pretensão de revelar, a partir das experiências da professora-pesquisadora com as três ciganas participantes, a verdade sobre elas.

"Desde a infância que essas mulheres vêm me subjetivando e me constituindo enquanto sujeito. As primeiras experiências aconteceram em Viçosa, Minas Gerais, através de histórias que minha família materna contava. No lugarejo, onde meus avós moravam, tinha muitas fazendas e sítios, ouvia-se dizer que em determinadas épocas do ano chegavam ciganos(as) para acamparem nas redondezas desse lugar. Certa vez, um grupo de mulheres ciganas aproximou da porteira do sítio da casa do meu tio avô, duas primas sozinhas e com medo, acabaram por expulsá-las de lá. Segundo relatos familiares, as ciganas, com raiva, praguejaram minhas primas, que vieram adoecer e morrer pouco tempo depois. Também escutava que as ciganas roubavam crianças e roupas do varal das fazendas e sítios.”

Essas histórias ficaram presentes no imaginário da professora-pesquisadora e voltaram com força a partir dos relatos de sua mãe, também professora, quando essa começou a lecionar para crianças ciganas numa escola que fica bem próxima da comunidade cigana em que a pesquisa foi realizada. Ao compartilhar suas experiências com os/as alunos/as ciganos/as e suas respectivas famílias, os relatos eram organizados por questões de gênero, principalmente no que diz respeito às funções sociais desempenhadas pela mulher cigana: as funções domésticas, matrimoniais e maternas. $\mathrm{O}$ maior incômodo era com o abandono escolar das meninas ciganas. As famílias retiram as crianças da instituição, por volta de 11 e 12 anos de idade, para se casarem. A pesquisa nasceu dessa inquietação da mãe-professora, revelada à filha, a partir de dois aspectos, uma dupla inquietação, tanto o fato de as meninas abandonarem a escola muito cedo, quanto o fato de se casarem nessa idade. Duas inquietações que só se tornam incômodos a partir dos discursos e conhecimentos sobre juventude e escola. As inquietações da mãe também se tornam inquietações para a filha professora, que, tomada por esses incômodos e suas lembranças de infância, organizou a pesquisa. 
Abandonar a escola com 12 anos para casar vai de encontro com o que mãe e filha, ambas professoras, acreditam como valor. Mas o que é valor para elas não parece ter o mesmo significado para a comunidade cigana. São mulheres que se incomodam com a forma de ser e se comportar de outras mulheres. Segundo Scott (1995: 72), gênero é “o caráter fundamentalmente social das distinções baseadas no sexo", sendo uma categoria de análise importante para pensar as desigualdades entre homens e mulheres na sociedade, mas também no interior do próprio gênero. Essas desigualdades, como ressaltou Scott, não são biologicamente dadas, mas fruto de construções sociais e históricas (SCOTT, 1995). Esse entendimento é fundamental para problematizar as desigualdades de gênero presentes na cultura cigana.

"A minha aproximação com a temática de pesquisa vai muito além dessas experiências familiares. O contato com os estudos de gênero, os estudos foucaultianos e os estudos que se aproximam da perspectiva pós-estruturalista tem me movimentado e convidado a ser uma outra pessoa e a pensar a cultura cigana de uma outra maneira. O modo como sou subjetivada hoje, diz de uma outra mulher, mais atenta, desconfiada, curiosa, com mais coragem e força diante da vida. Essa mulher que tenho me tornado me faz querer sair do lugar, me movimenta a pesquisar um tema que até pouco tempo, era motivo de medo, certezas e preocupações. Mesmo que lentamente, estou conseguindo extrapolar limites e barreiras em relação à cultura cigana."

A experiência do sujeito com a escrita e com a pesquisa está ligada a outras palavras carregadas de sentidos: subjetividades, educação e gênero. Mais do que palavras, são conceitos que podem ser entendidos de diferentes maneiras, pois são construídos a partir de variadas concepções de mundo e vida e através de múltiplas perspectivas teóricas e políticas. A perspectiva foucaultiana nos ensina a problematizar "os modos convencionais de produção e divulgação do que é admitido como ciência; questionam a concepção de um poder central e unificado regendo o todo social" (LOURO, 1997: 29). São estudos que abrem espaço para problematizarmos as verdades rígidas, fixas e totalizantes em relação à história, aos processos educativos e à constituição das mulheres ciganas.

Anderson Ferrari (2010) ressalta que o "sujeito se constitui sempre historicamente", uma compreensão importante para pensarmos nos "diferentes processos de constituição das subjetividades". Para o autor, subjetividades seriam "esses modos pelos quais nos tornamos sujeitos", esses "modos de subjetivação que são construídos ao longo da História e se desenvolvem historicamente como práticas de si” (FERRARI, 2010: 9). São processos contingentes, plurais e singulares, que podem ser constituídos, dentre tantos outros modos, na história e na cultura. 
O sentido de "educação" que está presente nesta pesquisa é mais abrangente, não se restringindo à escola. É um entendimento de educação com processo educativo de constituição dos sujeitos, que vai da escola à cultura cigana. Marisa Vorraber e Paula Deporte de Andrade (2015) pensam a educação a partir das contribuições dos Estudos Culturais $^{3}$, que nos convidam a pensar que a educação ocorre em vários e diferentes espaços culturais. De acordo com as autoras, a institucionalização desses estudos, em meados dos anos 1960, na Inglaterra, contribuiu para ampliar o leque de análises de muitos campos de conhecimentos, inclusive a Pedagogia:

A internacionalização da pesquisa e a importação de ideias pedagógicas facilitada pelo processo de globalização - vivenciado mais intensamente pelas sociedades do século XX a partir dos anos 50-60 - colaboraram para transformações na noção de pedagogia. As discussões produzidas em muitos países, na década de 1960, sobre os conceitos de currículo oculto e pedagogia invisivel, por exemplo, já indicavam, que a pedagogia não se limitava a práticas escolares explícitas ou institucionalizadas (ANDRADE; VORRABER, 2015: 49).

Foi nesse cenário, de transformações históricas, culturais e sociais, que "o conceito de pedagogias culturais surgiu como uma produtiva ferramenta teórica acionada para discutir a relação entre artefatos da cultura e processos educativos" (ANDRADE; VORRABER, 2015). Assim, essa perspectiva de educação mais ampla ajudou a pensar os processos de constituição das mulheres ciganas.

A palavra "gênero" refere-se ao caráter sociocultural das diferenças percebidas entre homens e mulheres. O conceito pretende se referir "ao modo como as características sexuais são compreendidas e representadas ou, então, como são "trazidas para a prática social e tornadas parte do processo histórico" (LOURO, 1997: 22). Gênero seria, portanto, os saberes que estabelecem "significados para as diferenças corporais" (SCOTT, 1995: 13). A despeito de serem múltiplas as possibilidades de constituição das mulheres na sociedade, há uma aproximação nos modos de ser mulher que, independente da cultura, perpassa o gênero. As relações desiguais construídas ao longo da história afetam tanto as mulheres ciganas quanto as mulheres não ciganas, uma vez que ambas são educadas para serem esposas, mães e donas de casa. Essa educação tenta colocar os corpos femininos em uma posição de inferioridade e submissão em relação aos homens.

Esse investimento educativo é construído desde criança. Aprendemos, com os brinquedos, que devemos lavar, passar, cozinhar, limpar, cuidar dos(as) filhos(as) e do marido. As bonecas, as panelinhas e as brincadeiras de mamãe-filhinha vão nos 
ensinando que o nosso lugar é no espaço doméstico. A reiteração dessas funções ao longo da vida vai naturalizando as relações de gênero em nossa sociedade. Judith Butler pensa essa reiteração normativa a partir da teoria da performatividade de gênero. Desse modo, o gênero seria um conjunto de atos, gestos e desejos repetidos que dão "a aparência de uma substância, de uma classe natural de ser" (BUTLER, 2003: 59).

Vivemos em um mundo em que se passam muitas coisas, mas talvez poucas coisas nos aconteçam, nos toquem, nos incomodem e desacomodem. O excesso de informação, de opinião, de trabalho e a falta de tempo dificultam a experiência (LARROSA, 2002: 23). O sujeito da experiência é constituído por "acontecimentos que marcam, o tiram do lugar, levam para fora de si mesmo, trazendo ressignificações, de tal forma que o sujeito não é o mesmo de antes" (FRANÇA, 2019: 28). Mas, como viver a experiência? De que modo podemos vivenciá-la?

Para ser atravessado pela experiência, o sujeito precisa se ex(por), estar aberto e receptivo para possibilitar a transformação de si. Tornar-se um sujeito ex(posto) é estar aberto à vulnerabilidade e ao risco que a travessia da experiência nos proporciona. É sair das posições fixas, que erguem sujeitos firmes em seus próprios saberes, poderes e vontades. O sujeito autodeterminado é incapaz de se ex(por) a uma experiência e a uma transformação. Não se pode vivenciar a experiência sem "uma lógica da paixão, uma reflexão do sujeito sobre si mesmo enquanto sujeito passional" (FRANÇA, 2019: 26) que se responsabiliza com o outro, coloca-se para fora de si. Uma paixão que leva ao deslocamento, ao tensionamento e à experiência.

"Como pesquisadora tenho a responsabilidade ética com a história e a vida das mulheres ciganas, e esse processo exige de mim constantes afastamentos e problematizações do modo como fui constituída em relação a elas".

O processo de escrita tem sido uma oportunidade de vivenciar essa experiência de desprendimento.

"Encontrar com livros-experiências tem possibilitado mudanças do meu olhar em relação às mulheres ciganas, um processo que vem permitindo uma transformação de mim mesma".

Para Foucault (2009), esses livros têm a capacidade de nos arrancar de nós mesmos, de transformar o sujeito e seu modo de pensar. "Cuando escribo, lo hago, por sobre todas las cosas, para cambiarme a mí mismo y no pensar lo mismo que antes" (FOUCAULT, 2009: 9). São escritos que questionam explicações universais e totalizantes e que consideram a influência dos discursos, da história e dos efeitos de 
saber e poder na constituição dos sujeitos e das subjetividades. São abordagens teóricas que

não gostam de explicações universais, nem de totalidades, nem de completudes ou plenitudes. [...] Não acreditam na "suposta" autonomia do sujeito ou da subjetividade [...]. Consideram o sujeito um efeito da linguagem, dos textos, do discurso, da história, dos processos de subjetivação (PARAÍSO, 2004: 286).

As experiências que compõem o trabalho com mulheres ciganas são de caráter provisório e situado. Não há a pretensão de generalizar os modos pelos quais essas experiências são dadas, uma vez que elas podem acontecer de distintas maneiras, no interior das culturas e nos variados tempos históricos. Não é um trabalho que diz de todas as comunidades ciganas em todos os tempos; diz de três mulheres ciganas em uma dada comunidade e tempo. Nesse sentido, a experiência é tomada como "forma histórica de subjetivação" (CASTRO, 2009: 161), como "correlação, em uma cultura, entre campos de saber, tipos de normatividade e formas de subjetividade" (FOUCAULT, 1984: 10).

Se, conforme Foucault, toda experiência está permeada por jogos de verdade, relações de poder e formas de relação consigo mesmo e com os outros, não há como separar a experiência da trama histórica na qual ela acontece. Ao aproximar pensamento e história, Foucault problematiza a experiência.

Uma história que não seria aquela do que poderia existir de verdadeiro nos conhecimentos, mas sim uma análise dos 'jogos de verdade', dos jogos do verdadeiro e do falso através dos quais o ser se constitui historicamente como experiência, ou seja, como podendo e devendo ser pensado (FOUCAULT, 1984: 11).

As falas da professora-pesquisadora e as experiências das mulheres ciganas têm um lugar no pensamento e na história. É desse lugar que os acontecimentos foram narrados, lembrados e ressignificados. A memória está atrelada a possibilidades de mudanças, visto que, ao contar uma história passada, nós a ressignificamos com experiências do presente. De acordo com Raphaela Santos (2009: 79), “quem consegue construir narrativas sobre seu passado, consegue reconstruir uma vida, se submete a uma experiência, através da escolha daquilo que se passou consigo. Isso pode nos deixar aptos a adotar novos projetos de vida".

Foram as memórias da professora-pesquisadora que deram origem ao trabalho de investigação, a partir do momento que foram ressignificadas com elementos e marcas do presente. As memórias da infância, as lembranças sobre as mulheres ciganas e os relatos familiares contribuíram para ela colocar sob suspeita os modos de subjetivação, 
entendidos como um "conjunto de discursos colocados em movimentos segundo um corpo de regras [...] comandam, em nós, maneiras de perceber, julgar, pensar e agir" (VEIGA-NETO, 2016: 95). Como esses discursos chegaram à família da professorapesquisadora? Como foram produzidos? Estamos partindo do pressuposto de que não foram os familiares que construíram esses discursos, os quais já faziam parte da organização do mundo antes mesmo de eles nascerem. São discursos que já estão, há muito tempo, circulando e influenciando a constituição dos sujeitos.

"Tive a oportunidade de confrontar esses discursos familiares e do senso comum na minha juventude, momento em que me deparei pela primeira vez com as mulheres ciganas. Esse encontro aconteceu no centro de Juiz de Fora, já nos anos 1990. Estava passeando com a minha mãe, quando avistei de longe, algumas ciganas fazendo leitura de mãos. O modo como elas trajavam, vestidos longos, bem coloridos, bordados e brilhantes, chamou muita atenção. Eram roupas que destoavam muito daquelas usadas pela maioria das pessoas que circulavam na cidade, por isso estranhei. Tal estranheza não era sinônimo de algo feio, pelo contrário, ficava admirada com o colorido dessas vestimentas. Porém, ficava de longe, pois o medo não permitia tal aproximação. Avistar uma cigana era motivo de apreensão, minha mãe falava: "vamos atravessar a rua porque as ciganas podem nos abordar pedindo para ler a mão e nos roubar".

No relato acima, é interessante notar que o processo de identificação ocorre a partir das vestimentas das mulheres, ao contrário do homem cigano, que não tinha visível sua identidade no corpo e nas vestimentas. O medo não era direcionado aos homens ciganos, pois eles passavam despercebidos diante das duas professoras. Hoje não conseguimos fazer essa identificação com tanta facilidade, pois muitas mulheres ciganas estão deixando de usar os trajes típicos da cultura por causa do preconceito. $\mathrm{O}$ fato de as mulheres carregarem as marcas da cultura em seu corpo faz com que elas sejam mais expostas a sofrer ataques e atitudes de intolerância e hostilidade, como Paula Soria ${ }^{4}$ afirma:

a romi está mais exposta ao "outro", pois carrega as insígnias do grupo nas vestimentas, nos adornos e nos ofícios estigmatizados como a quiromancias. Dessa forma ela é a mais estigmatizada tanto nos contatos interétnicos como nas representações culturais (SORIA, 2016: 26).

As vestimentas ciganas acabam inscrevendo nos corpos dessas mulheres as marcas dos estereótipos ${ }^{6}$ e preconceitos $^{7}$. Essa imagem negativa acaba dificultando enxergá-las de outro modo. Como a construção desses conhecimentos constitui sujeitos? Para Foucault, o saber e o poder são interdependentes e ambos interferem na produção do conhecimento do sujeito: "é preciso considerar [...] que o sujeito que conhece, os objetos a conhecer e as modalidades de conhecimentos são outros tantos efeitos dessas 
implicações fundamentais do poder-saber e suas transformações históricas" (FOUCAULT, 2004: 30). Nesse sentido, não parece possível que o olhar da professora esteja desvinculado dos discursos produzidos a partir dessas relações saber-poder. A verdade, reverberada através desses discursos, dos saberes, dos poderes e da relação entre mãe e filha construíram o olhar da professora-pesquisadora para as mulheres ciganas de uma determinada maneira. Esse modo de olhar o outro a colocou em um lugar em relação a esse "outro" diferente dela, participando, assim, da sua constituição como mulher não cigana, por exemplo. É essa relação consigo, com o outro, com os discursos e com o que somos capazes de dizer de nós mesmos, dos nossos pertencimentos que nos constitui como "sujeitos".

Judith Butler defende o pensamento de que não há uma identidade fixa para a categoria "mulher", indo contra a ideia de "mulher" como essência. Ao colocarmos todas as mulheres em um modelo fixo de identidade, excluímos todas as outras possibilidades de sua construção. Portanto, a categoria mulher está em constante produção e não se aprisiona em nenhuma definição normativa e homogênea (BUTLER, 2003). A professora-pesquisadora e as ciganas estão inseridas na mesma categoria “mulher", porém não vivenciam essa experiência do mesmo modo. A maneira de olhar o outro diz dessas particularidades e dessas diferenças. A construção do sujeito não pode acontecer de forma individualizada e isolada, mas de maneira histórica e relacional. É preciso interagir com o "outro" para se constituir e afirmar enquanto sujeito. Falar que a identidade é relacional é dizer que ela acontece numa correlação com a diferença, ou seja, a "identidade-eu" (mulher não cigana) depende, para existir, da "identidade-outro" (mulher cigana). Isso traz à discussão o fato de que a marcação dessa identidade e dessa diferença envolve sistemas representativos e classificatórios que definem "quem sou eu" e "quem é o outro". Entender que "a cultura estabelece essas fronteiras e distingue essas diferenças" (WOODWARD, 2000: 41) possibilita compreender melhor o processo de construção da identidade.

Podemos pensar como a nossa cultura tem estigmatizado a identidade cigana ao longo da história, colocando-a como uma diferença que não precisa ser valorizada e nem respeitada.

"Pensei, por um bom tempo, que a minha identidade era superior à dos(as) ciganos(as), mas, hoje, tenho colocado sob suspeita esse pensamento".

Veiga-Neto (2007) nos ensina que não devemos aceitar de modo não 
problemático as bases pelas quais nos ensinaram a acreditar: "penso que se deve desconfiar das bases sobre as quais se assentam as promessas e as esperanças nas quais nos ensinaram a acreditar. Tudo indica que devemos sair dessas bases para, de fora, examiná-las e criticá-las" (VEIGA-NETO, 2007: 23). A curiosidade que levou à pesquisa acabou mobilizando a professora-pesquisadora a buscar novos conhecimentos, colocando sob suspeita sua forma de pensar e agir, impulsionando-a a alçar novos pensamentos, transformando-a, ao final, em uma outra professora e outra mulher.

Deborah Britzman (2010), em seu texto "Curiosidade, sexualidade e currículo", nos diz que "sem curiosidade o ser humano não seria capaz de aprender" (BRITZMAN, 2010: 89). A autora estimula um conhecimento por meio da liberdade à curiosidade, defende um conhecimento sobre a sexualidade através de esferas ligadas à paixão pelo desconhecido e à vontade de saber. Essa curiosidade é que faz sair da zona de conforto para buscar outras direções que pudessem, como a autora mencionou, "se mostrar(em) surpreendentes" (BRITZMAN, 2010: 85).

É o gênero que possibilita que a professora-pesquisadora tome suas experiências com as mulheres ciganas para problematizar a relação do conhecimento com a constituição dos sujeitos. Tanto "mulheres" quanto "ciganas" são resultado de construções sociais, culturais e históricas. Por isso, usamos o plural para nos referir a essas duas categorias, visto que esses processos são constituídos de variadas maneiras em uma dada sociedade e em um dado momento histórico. As mulheres ciganas também são constituídas de diferentes modos no interior de uma mesma cultura, por isso, a impossibilidade de falar delas de forma generalizante.

"O fato de estarmos inseridas em uma mesma sociedade nos faz compartilhar de algumas situações que estão relacionadas ao gênero feminino".

A responsabilidade pelos afazeres domésticos e o cuidado com os (as) filhos (as) não é algo específico da organização da cultura cigana, perpassa também outras culturas, como a nossa.

Essa perspectiva de gênero vem causando rupturas nos modos de pensar, ao colocar sob suspeita a naturalidade do conhecimento e a essência dos sujeitos. Assumir gênero como construção social e histórica é negar a possibilidade de existir uma única maneira de ser mulher cigana. Recuperando a celebre afirmação de Simone de Beauvoir, de que "ninguém nasce mulher: torna-se mulher", é importante dizer que essa expressão causou muito impacto entre as mulheres, pois passou a indicar 
que seu modo de ser e de estar no mundo não resultava de um ato único, inaugural, mas que, em vez disso, constituía-se numa construção. Fazer-se mulher dependia das marcas, dos gestos, dos comportamentos, das preferências e dos desgostos que lhes eram ensinados e reiterados, cotidianamente, conforme normas e valores de uma dada cultura (LOURO, 2008: 17).

Nesse sentido, o conceito de gênero é entendido de maneira plural, considerando que, para cada momento histórico, cada sociedade ou no seu interior, há concepções distintas para homens e mulheres. As mulheres ciganas, como também as outras mulheres, são constituídas a partir das relações que estabelecem na história com os outros sujeitos, sendo o gênero, nesse aspecto, relacional. De acordo com Joan Scott (1995), a compreensão de qualquer um dos gêneros não poderia existir através de um estudo inteiramente separado uma vez que

qualquer informação sobre as mulheres é necessariamente informação sobre os homens, que um implica o estudo do outro. Essa utilização enfatiza o fato de que o mundo das mulheres faz parte do mundo dos homens, que ele é criado nesse e por esse mundo masculino. [...] estudar as mulheres de maneira isolada perpetua o mito de que uma esfera, a experiência de um sexo, tenha muito pouco ou nada a ver com o outro sexo (SCOTT, 1995: 75).

Pensar o processo de constituição das mulheres ciganas não exclui o homem desse processo, visto que os gêneros se constituem a partir de uma relação de interdependência. Portanto, falar de mulheres ciganas é necessariamente falar dos homens e vice-versa. Para Anderson Ferrari e Roney Polato de Castro (2016), pensar a educação para os gêneros e para as sexualidades é considerar "os mecanismos utilizados para a constituição dos sujeitos, as intervenções promovidas sobre os corpos, as proibições, as normas estabelecidas, as relações interpessoais" (CASTRO; FERRARI, 2016: 17). Esses processos educativos, ao reforçarem normas e condutas acabam, muitas vezes, agindo na intensificação de preconceitos, discriminações e violências diversas.

\section{Considerações finais}

Ao longo do artigo, mostramos os efeitos dos encontros com mulheres ciganas na professora-pesquisadora nos seus processos de desconhecer para pensar e agir de forma diferente do que se faz. Foi esse processo que demonstramos para nos aproximar da formação inventiva que, segundo Rosimeri Dias (2015: 195), "se liga aos territórios escolares para provocar um exercício de colocar a atenção no presente e desformar, mais do que formar". Escrever a dissertação fez com que a professora-pesquisadora 
voltasse a atenção sobre si mesma a partir do que escutou das mulheres ciganas, daquilo que foi capaz de escutar e de dar vida como relato e como experiências de constituição do sujeito. Podemos dizer que nossas escritas acadêmicas, muitas vezes, partem das nossas experiências ou de experiências das outras pessoas participantes conosco das nossas investigações, de maneira que escrever sobre pessoas e seus processos de constituição, escrever sobre o que chamamos de "realidade" é participar do jogo político de atribuição de sentidos. Assim, vamos inventando novas narrativas e novos sujeitos que podem resistir ou mesmo subverter o que é conhecido, as "verdades". Olhar para esse processo de escrever sobre o que nos passa na formação continuada é uma forma de dar lugar para a formação inventiva como aquela que é capaz de nos fazer desprender-nos de nós mesmos, a partir do processo de nos inquietar conosco. É o que Foucault (2016) nos inspira a pensar a partir do ato de pesquisar e escrever.

No fundo, não escrevo porque tenho alguma coisa na cabeça, não escrevo para demonstrar aquilo que já, em meu foro interior e para mim mesmo, demonstrei e analisei. A escrita consiste essencialmente em empreender uma tarefa graças à qual e ao final da qual poderei, para mim mesmo, encontrar alguma coisa que não tinha visto inicialmente. Quando começo a escrever um estudo, um livro, qualquer coisa, não sei realmente aonde isso vai, nem em que vai dar, nem o que demonstrarei. Só descubro o que tenho para demonstrar no próprio movimento da escrita, como se escrever fosse precisamente diagnosticar aquilo que eu queria dizer no exato momento em que comecei a escrever. (FOUCAULT, 2016: 49).

Foi esse movimento de olhar para trás, ao final do trabalho, para "encontrar alguma coisa que não tinha visto inicialmente" que a professora-pesquisadora exercitou e que nos motivou a escrever, visto que isso diz de um processo de transformação de si que nos aproxima da formação inventiva. A professora que iniciou o trabalho não é a mesma que se coloca ao longo da escrita. Trata-se de uma outra mulher, uma outra professora, que nos demonstra o trabalho inseparável da formação de professoras juntamente com a formação do sujeito.

\section{Referências}

ANDRADE, Paula Deporte de. Usos e possibilidades do conceito de pedagogias culturais nas pesquisas em estudos culturais em educação. Textura, vol. 17, $\mathrm{n}^{\circ} .34$, mai./ago.2015.

ANDRADE, Paula Deporte de; COSTA, Marisa Vorraber. Usos e possibilidades do conceito de pedagogias culturais nas pesquisas em estudos culturais em educação. Textura, Canoas, vol. 17, n 34, mai./ago., 2015, p. 48-63. 
BRITZMAN, Deborah. Curiosidade, sexualidade e currículo. In: LOURO, Guacira Lopes (organizadora). O corpo educado: pedagogias da sexualidade. $3^{\text {a }}$ ed. Belo Horizonte: Autêntica, 2010, p. 83-111.

BUTLER, Judith. Problemas de Gênero: Feminismo e Subversão da Identidade. Rio de Janeiro: Civilização Brasileira, 2003.

CASTRO, Edgardo. Vocabulário de Foucault: um percurso pelos seus temas, conceitos e autores. Belo Horizonte: Autêntica, 2009.

CASTRO, Roney Polato de. Experiência e constituição de sujeitosdocentes: relações de gênero, sexualidades e formação em Pedagogia. 256p. Tese de Doutorado. Programa de Pós-Graduação em Educação. Universidade Federal de Juiz de Fora, Juiz de Fora, MG, 2014.

CASTRO, Roney Polato de; FERRARI, Anderson. Como as imagens nos educam para os gêneros e as sexualidades? - Cultura visual e formação docente. Revista Linhas, Florianópolis, vol. 17, nº 34, p. 08-27, maio/ago. 2016.

DIAS, Rosimeri de Oliveira. Pesquisa-Intervenção e formação inventiva de professores. Revista Polis e Psique, Porto Alegre: UFRGS, vol. 5 (2), 2015.

FERRARI, Anderson. Apresentação: Sujeitos, Subjetividades e Educação. In: (Org). Sujeitos, Subjetividades e Educação. Juiz de Fora: UFJF, 2010, p. 7-18.

FERRARI, Anderson. "Poeticamente silenciosa": cinema e a formação ética estética dos sujeitos. In: FERRARI, Anderson; POLATO, Roney. (Orgs.). Política e Poética das imagens como processos educativos. Juiz de Fora: Ed. UFJF, 2012.

FISCHER, Rosa Maria Bueno. Verdades em suspenso: Foucault e os perigos a enfrentar. In: COSTA, M. V. Caminhos Investigativos II: outros modos de pensar e fazer pesquisa em educação. Rio de Janeiro: Lamparina Editora, 2007, p. 49 - 70.

FOUCAULT, Michel. História da sexualidade II: O uso dos prazeres. Rio de Janeiro: Graal, 1984.

FOUCAULT, Michel. Vigiar e Punir. Tradução de Raquel Ramalhete. Petrópolis: Editora Vozes, 2004.

FOUCAULT, Michel. Polêmica, política e problematização (1984). In: FOUCAULT, Michel. MOTTA, Manoel Barros da (org.). Ditos \& escritos V: ética, sexualidade, política.. Rio de Janeiro: Forense Universitária, 2006, p. 225-233.

FOUCAULT, Michel. Cómo nace um libro-experiencia. In: FOUCAULT, M. El yo minimalista e otras conversaciones. Buenos Aires: La Marca, 2009, p. 9-17.

FOUCAULT, Michel. O belo perigo. Belo Horizonte: Autêntica, 2016.

FRANÇA, Filipe Gabriel Ribeiro. "Para fazer pensar e entreter”: educação, produção de corpos, sujeitos e masculinidades na revista Junior. Tese de Doutorado. Programa de Pós-Graduação em Educação. Universidade Federal de Juiz de Fora, Juiz de Fora, MG, 2019.

LARROSA, Jorge. Notas sobre a experiência e o saber da experiência. Revista Brasileira de Educação, nº 19, 2002.

LIMA, Maria Manuel. Considerações em torno do conceito de estereótipo: uma dupla abordagem. Lisboa: Aveiro, 1996. 
LOPES, Maura Corcini; VEIGA-NETO, Alfredo. Para pensar de outros modos a modernidade pedagógica. ETD - Educ. Tem. Digital, Campinas, v.12, n.1, p.147-166, jul./dez. 2010.

LOURO, Guacira Lopes. Gênero, sexualidade e educação: uma perspectiva pósestruturalista. Petrópolis: Editora Vozes, 1997.

LOURO, Guacira Lopes. Conhecer, pesquisar, escrever... Educação, Sociedade e Culturas. Porto, PT, Edições Afrontamento, v. 1, no 25, 2007, p. 235-245.

LOURO, Guacira Lopes. Gênero e sexualidade: pedagogias contemporâneas. ProPosições, Campinas, v.19, nº 2, p.17-23, maio/ago. 2008.

MARSHALL, James. Michel Foucault: pesquisa educacional como problematização. In: PETERS, Michael e BESLEY, Tina. Por que Foucault? Novas diretrizes para pesquisa educacional. Porto Alegre: Artmed, 2008.

MELO, Dias de; SILVA, Gislaine de Fátima Ferreira; RIBEIRO, Cláudia Maria. Águas revoltas: mergulhos na indefinição. Um inundar de questionamentos sobre a loucura, diferenças e transgeneridade. In: V Congresso Internacional em Estudos Culturais: Género, Direitos Humanos Ativismos, 2016, Aveiro (Portugal). Anais ... Grácio, 2016, p.231- 238.

PARAÍSO, Marlucy Alves. Pesquisas pós-críticas em educação no Brasil: esboço de um mapa. Cadernos de Pesquisa, São Paulo, vol.34, no 122, p.283-303, maio/ago. 2004.

RIBEIRO, Tiago; SAMPAIO, Carmen Sanches; SOUZA, Rafael de. Conversa como metodologia de pesquisa: por que não? Rio de Janeiro: Ayvu, 2018.

SANTOS, Raphaela Souza dos Santos. Entre lembranças e silêncios: memórias de mulheres alunas de EJA. 139 p. Dissertação de Mestrado. Programa de PósGraduação em educação. Universidade Federal de Juiz de Fora, Juiz de Fora, MG, 2009.

SCOTT, Joan. Gênero: uma categoria útil de análise histórica. Educação \& Realidade. Porto Alegre, vol. 20, nº 2, jul./dez, 1995. p.71-99

SIMÕES, António. Estereótipos relacionados com os idosos. Revista Portuguesa de Pedagogia, p. 207-234, 1985.

SORIA, Ana Paula C.B. “Juncos ao Vento”: Literatura e Identidade Romani (cigana) El alma de los parias, de Jorge Nadick. 330 p. Tese de Doutorado. Programa de Pós-Graduação do Departamento de Teoria Literária e Literaturas. Universidade de Brasília, Distrito Federal, 2015.

SORIA, Paula. Nas tessituras da emergente literatura romani (cigana): subalternidade, gênero e identidade em questão. Pró-Revistas, nº 27, p.21-31, jan/jun. 2016.

VEIGA-NETO, Alfredo. Olhares. In: COSTA, Marisa Vorraber (Org.). Caminhos investigativos I: novos olhares na pesquisa em educação. Rio de Janeiro: Lamparina Editora, 2007, p. 23-38.

VEIGA-NETO, Alfredo. Foucault \& a Educação. $3^{\circ}$ ed. Belo Horizonte: Autêntica, 2016.

WOODWARD, Kathryn. Identidade e diferença: uma introdução teórica e conceitual. In: SILVA, Tomaz Tadeu da (org.). Identidade e diferença: a perspectiva dos Estudos Culturais. Petrópolis, RJ: Vozes, 2000, p. 7-72. 


\title{
Gláucia Siqueira Marcondes Secretaria de Educação do Estado de Minas Gerais; Universidade Federal de Juiz de Fora \\ E-mail: Glauciamarianinho@hotmail.com
}

\author{
Anderson Ferrari \\ Universidade Federal de Juiz de Fora \\ E-mail: aferrari13@globo.com
}

\footnotetext{
1 As falas da professora-pesquisadora irão aparecer sempre em recuo e sempre entre aspas, para diferenciá-las das citações das autoras e autores, que aparecem quer em itálico, quer sem recuo.

${ }^{2}$ Para manter o anonimato das três ciganas, foram adotados nomes fictícios.

3 Os Estudos Culturais têm sua origem na fundação, em 1964, do Centro de Estudos Culturais Contemporâneos, na Universidade de Birmingham, na Inglaterra. Esse campo de estudos se espalhou pelo restante do mundo e suas publicações recentes são bem diferentes dos trabalhos que inauguraram.

${ }^{4}$ Primeira mulher cigana a concluir o doutorado na América Latina, em 2015, com a tese "Juncos ao vento": literatura e identidade romani (cigana): El alma de los parias, de Jorge Nedich.

${ }^{5}$ Leitura de mãos.

6 Entendemos estereótipo como "[...] uma matriz de opiniões, sentimentos, atitudes e reações dos membros de um grupo, com as características de rigidez e homogeneidade" (SIMÕES, 1985: 207).

7 Os estereótipos constituem frequentemente a base dos preconceitos, apresentando um forte enraizamento histórico e cultural: contêm um aspecto cognitivo de pré-juízo e encontram-se profundamente arreigados à forma como, tradicionalmente, os grupos sociais se relacionam entre si forma essa que consideram legítima, pois percepcionam-se de um modo determinados, que, muitas vezes se encontra consolidado historicamente (LIMA, 1996).
} 